\title{
Managing Variability in Algal Biomass Production through Drying and Stabilization of
}

\section{Feedstock Blends}

Bradley D. Wahlen", Mohammad S. Roni, Kara G. Cafferty, Lynn M. Wendt, Tyler L. Westover, Dan M. Stevens, and Deborah T. Newby

Idaho National Laboratory, Idaho Falls, ID

*Corresponding author: Phone number: +1 208-526-2425, Email address:

bradley.wahlen@inl.gov (B.D.Wahlen)

\section{Abstract:}

The uncertainty and variability of algal biomass production presents several challenges to the nascent algal biofuel industry, including equipment scaling and feedstock supply. Ideally, on-site processing equipment will be scaled to minimize overall biofuel production costs, which means at times biomass production could exceed down-stream processing capacity due to seasonal variation. Biomass produced in excess of conversion capacity during summer months must be stabilized by some method, such as drying, until needed later in the year. Because of algae's high moisture content and its cohesive nature, drying is challenging. Blending algae with terrestrial biomass may provide a cost-effective method to enable drying and stabilization of algae by reducing moisture content and improving rheological (i.e. flowability) properties. To test the technical feasibility of this approach, bench-scale rotary drum dyers were constructed and tested with blends of algae (Scenedesmus sp.), ground pine (2 mm grind), sorghum, corn stover (6 mm), sieved sand, and dried algae. In these studies, blends up to $40 \%$ algae exhibited drying behavior similar to that of pine alone, and reached dryness ( $2 \%$ moisture) in half of the time it took to dry 
algae alone. Thermogravimetric analyses performed on blends and neat blend materials provided drying curves consistent with the bench-scale dryers. Preliminary logistics analysis for production-scale operations were performed to determine cost and availability of feedstock materials for blending as compared to drying algae directly. This analysis indicates that revenue lost due to idle processing capacity had a significant impact on the per gallon gasoline equivalent feedstock cost. The blending approach, described herein, reduced feedstock-related costs, including procurement, drying, and storage by $35 \%$ relative to drying algae directly. Our results indicate that blending algae with terrestrial biomass enables the use of rotary dryers and has the potential to improve overall algal biofuel economics.

Abbreviations

HTL, hydrothermal liquefaction; wb, wet basis; CPVC, chlorinated polyvinyl chloride; PVC, polyvinyl chloride; TGA, thermogravimetric analysis; IAF, integrated assessment framework; BLM, biomass logistics model; BTU, British thermal unit; AFDW, ash-free dry weight; CAP, combined algal processing; gge, gallon gasoline equivalent

Keywords

Algae biofuels; hydrothermal liquefaction; algae biomass storage; blending; economic feasibility; sustainability

\section{Introduction}

The need for sustainable alternatives to petroleum-based fuels has led to increased interest in microalgae as a source of biofuels, due to their high rate of productivity and high lipid content $[1,2]$. Research into the use of microalgae as a fuel source has focused on every aspect of the process including strain development [3], cultivation [4], harvesting and dewatering [5], and 
conversion to fuel [6,7]; detailed techno-economic studies have been made to understand how each new technology affects the cost of fuel production [8-11]. A major challenge to the development of economical algal farms is the variability in algal biomass productivity due to seasonal variations in temperature and insolation. In some locations otherwise well suited for algal production (e.g. water, nutrients), large variability between summer and winter production, which can be as high as 10:1, creates a challenge to optimally scale downstream processing equipment [9,11]. Given the high cost of algal biomass production ( $74 \%$ of the final fuel cost [9]), the value of excess biomass must be captured by either scaling conversion facilities to accommodate maximum algal biomass productivity or by preserving excess biomass until conversion capacity becomes available. A recent study on location-dependent scaling of algae biofuel production facilities determined that conversion facilities were economically scaled when their conversion capacity was exceeded $10-30 \%$ of the time, highlighting the need for costeffective approaches to algae preservation [13].

Harvested algal biomass is a high moisture, high nutrient feedstock that begins to degrade almost immediately upon harvest, thereby requiring stabilization if it is not processed within hours of harvest. Algal biomass can suffer dry matter losses up to $20 \%$ within a week as a result of respiration and microbial degradation [14]. Reducing moisture content to below $15 \%$ is a common preservation strategy for lignocellulosic biomass [15] and is likely to be sufficient for algae biomass preservation. With few exceptions, drying experiments conducted in this study were continued until algae/terrestrial biomass blends reached moisture contents below $10 \%$ at which point they were considered stable.

The literature describing algal biomass drying is limited and has primarily focused on preserving Arthrospira platensis biomass (spirulina) for the food market. A number of different 
technologies, such as spray drying, freeze drying and solar drying have been employed to dry spirulina [16-18]. While solar drying was the least costly method employed, it also took the longest time, required a large area of land, and resulted in lower biomass quality [16]. Although spirulina dried by spray drying or lyophilization resulted in high quality biomass, these approaches are considered to be too expensive for algae biofuels applications [16]. There are many other mature drying technologies (e.g. paddle dryer, tray dryer, fluidized bed dryer, etc.) that have not been reported in the literature for their use in drying algae. In this paper, an approach is developed to dry microalgal biomass in a rotary drum dryer. Rotary drum dryers are widely used to dry lignocellulosic biomass because they are highly flexible and capable of drying products with a wide range of moisture contents, particle sizes, and flow properties [19]. This approach to drying algae has also been used in techno-economic models for algae biofuel production $[9,11,20]$.

The drying behavior of a material in a rotary drum dryer is highly dependent on the flow properties of the material, and rotary driers are generally less effective for sludges than freeflowing materials. Algae slurries at 20\% solids (wet basis (wb)) exhibit flow behavior that more closely resembles that of sludges than free-flowing materials, so it is anticipated that modifications to the dryer or algal slurry will be needed for efficient drying. Sludge-like materials are often characterized as "sticky", meaning that they have a tendency to agglomerate and adhere to contact surfaces. The cohesive and adhesive tendency of sludges limits the airsolids contact area and also limits heat and mass transfer within the material [21]. Due to mass transfer limitations, sludge-like materials undergo drying at the material surface more quickly relative to the interior, forming an outer crust that further interferes with removing moisture from the interior [22,23]. Several industries have overcome this challenge through blending their 
sludges with dry material. Arjone et al. mixed an olive oil waste product, which has similarities to a $20 \%$ solids algae slurry, with previously dried waste to reduce the moisture content and prevent agglomeration [24]. Industrial drying equipment manufacturers recommend blending sludges with dry product to reduce moisture content and to obtain compatible rheological properties [25]. Blending algae with terrestrial biomass provides an opportunity to reduce the starting moisture content and improve the physical properties (e.g. flowability) of the blend, which decreases drying costs using a rotary drum dryer. The final algae/terrestrial biomass blended product can be shelf stable and compatible with hydrothermal liquefaction (HTL) conversion or other conversion technologies or end uses, with both pine and algae contributing to the final product yield.

This paper assesses the technical and economic feasibility of blending algae with terrestrial biomass prior to drying. The technical feasibility is determined by evaluating the drying characteristics of algae blended with terrestrial biomass (pine or other lignocellulosic biomass) at ratios ranging from $20-80 \%$ algae (dry matter basis) in a bench-top rotary drum dryer. The improved flowability and reduced starting moisture content of algae blended with other materials is anticipated to enhance drying rates and reduce the cost of drying. The economic feasibility is evaluated through logistical analysis by assessing the quantities of terrestrial biomass needed for blending and determining the relative costs of bringing the two feedstocks together to create the blend. The feedstock-related costs from two alternate scenarios of managing algal biomass produced in excess of processing capacity are evaluated. The base case scenario involves drying excess algae directly, while the second considers drying algae as a blend with pine. Although the blending approach is developed with HTL as the focal conversion technology, adaptations are 
discussed that would produce dried algae using a rotary drum dryer compatible with other algae fuel conversion pathways, such as lipid extraction and upgrading [26].

\section{Materials and methods}

\subsection{Materials}

Two sources of algae biomass were used in completing this research. Scenedesmus dimorphus algal biomass was provided by Prof. Bruce Bugbee, Utah State University. Briefly, microalgal biomass was cultivated in vertical flat plate photobioreactors $(5 \mathrm{~cm}$ pathlength) until reaching stationary phase. S. dimorphus was cultivated in Bristol media [27] The biomass was harvested and dewatered to $28.5 \%$ solids (wb) by a combination of crossflow filtration and centrifugation, then frozen until needed. Scenedesmus sp. was provided by the Arizona Center for Algae Technology and Innovation (AzCATI, Arizona State University, Mesa, AZ) as frozen paste with a solids content of $16.6 \%(\mathrm{wb})$. The algae biomass was thawed at $4^{\circ} \mathrm{C}$ prior to use and was used either without modification or blended with terrestrial biomass or sand. Loblolly pine ground to $2 \mathrm{~mm}$ (top size) with a Wiley Mill (model 4, Thomas, Swedesboro, NJ) and dried to a moisture content of $6.3 \%$ moisture (wb), unless otherwise noted. For experiments examining the drying behavior of wet pine, water was added to the ground pine and moisture was allowed to equilibrate at $4^{\circ} \mathrm{C}$ for 24 hours before use. Single pass, $6 \mathrm{~mm}$ grind sorghum was used fresh (78.5\% moisture, wb) or dry (6.5\% moisture, wb) for blending with algae. Additionally, corn stover (6 mm grind) was also used fresh (46.6\% moisture, wb) or dry (8\% moisture, wb). The sand used in some experiments was obtained from a local building supply store.

\subsection{Biomass blending}

Algae and pine were blended together in ratios ranging from 20-80\% algae on a dry mass basis. Wet algae (71.5\% moisture), which had consistency similar to tomato paste, was added to $2 \mathrm{~mm}$ 
grind pine (6.3\% moisture) in varying ratios to achieve targeted algae/pine blends (e.g. 50\% algae, $50 \%$ pine on a dry mass basis). Algae and pine were blended together using a grout mixer paddle and a cordless power drill in a clean 5 gallon pail. Moisture content of each blend was determined gravimetrically after incubation at $105^{\circ} \mathrm{C}$ for at least 24 hours. Blends with algae and other blend materials (sorghum, corn stover, sand, and dry algae) were achieved in a similar manner.

\subsection{Shear test}

Specific shear strength and unconfined yield strength measurements were performed for ground pine ( $2 \mathrm{~mm}$ top size) that had been rehydrated to 59\% moisture and for blends of algae biomass and ground pine ( $2 \mathrm{~mm}$ top size, $6 \%$ moisture, wb) consisting of 30\%, 40\%, and 50\% algae. Shear tests were conducted in accordance with ASTM D6773-08 using an automated Schulze ring shear instrument (Dietmar Schulze Schüttgutmesstechnick, Wolfenbüttel, Germany), and a size $\mathrm{S}$ shear cell (outer diameter of $6 \mathrm{~cm}$ and inner diameter of $3 \mathrm{~cm}$ ). Briefly, each material was subjected four times to the same preshear compression stress $\left(\sigma_{p r e}\right)$ while varying the shear compression stress $\left(\sigma_{\text {shear }}\right)$ each time to obtain a yield locus [28]. Three or more yield locus curves obtained using different values of preshear compression stress $\left(\sigma_{\text {pre }}\right)$ were used to construct a flowability curve.

\subsection{Bench-scale drum dryer}

A simple bench-scale rotary drum dryer was utilized to assess the technical feasibility of drying algae blends. The dryer was constructed of a six inch diameter CPVC nipple and two six inch PVC caps. The interior of the drum was exposed to the outside environment through approximately 100 holes ( $8 \mathrm{~mm}$ diameter) made in each cap. Biomass was retained within the drum by a thin permeable membrane affixed to the interior of the cap. The membrane was 
protected from abrasion by a plastic mesh screen. Lifts were placed within the interior of the drum to aid drying. Each drum was weighed periodically to determine moisture loss. The base of a 1-gallon rock tumbler served as the rotating mechanism for each drum design (Supplementary Figure 1).

\subsection{Biomass drying experiments}

The bench-scale dryers were placed within an environmental chamber set at $50^{\circ} \mathrm{C}$. The temperature within the chamber was monitored continuously using a T-type thermocouple measurement device (NI USB-TC01, National Instruments, Austin, TX). For each experiment, $150 \mathrm{~g}$ (dry weight) of material was placed within the drum. Each drum was continuously rotated within the environmental chamber. Drum weights were recorded periodically to determine the amount of moisture lost until a constant weight was reached. Once dry, drums were disassembled and the moisture content of the biomass was determined gravimetrically by measuring the change in mass of the material after incubation at $100^{\circ} \mathrm{C}$ for at least 24 hours.

\subsection{Thermogravimetric analysis}

The drying rate of blends $(20 \%, 40 \%, 60 \%$, and $80 \%$ algae), moist pine ( $44 \%$ moisture, wb), and algae alone were determined in triplicate by thermogravimetric analysis (TGA). An equal amount of each material $(690 \mathrm{mg})$, on a dry matter basis, was placed within a LECO thermogravimetric analyzer (model TGA701, LECO Corporation, St. Joseph, MI). Samples were heated from $29^{\circ} \mathrm{C}$ to $107^{\circ} \mathrm{C}$ at a rate of $6^{\circ} \mathrm{C} \min ^{-1}$ and held at $107^{\circ} \mathrm{C}$ until each sample reached a constant weight. Throughout the analysis, the weight of each sample was continuously measured one after another; the measurement interval between samples was approximately $15 \mathrm{~s}$, while the interval between measurements within a sample was on average $288 \mathrm{~s}$. Moisture content was determined by Equation 1, 


$$
\% \text { Moisture }=\frac{\left(w_{i}-W_{f}\right)}{W_{i}} \times 100
$$

where $w_{i}$ is the initial weight of the sample and $w_{f}$ is the final weight. TGA analysis was used to calculate the moisture ratio for each sample according to Equation 2.

$$
\text { Moisture Ratio }=\frac{M_{t}}{M_{i}}
$$

The moisture ratio is a measure of the amount of moisture remaining in a sample, where $M_{t}$ is the moisture content of a sample at any time $t$ and $M_{i}$ is the initial moisture content.

\subsection{Scenarios}

The object of this paper is to assess the technical and economic feasibility of using terrestrial biomass as a blending feedstock to aid the drying and storage of seasonal excess algal production. To make this assessment, techno-economic analysis was utilized to compare the costs associated with blending algae to the base case, drying excess algae alone (Figure 1). The scenarios considered to manage uncertainty in algal productivity in this analysis were as follows:

\footnotetext{
Algae-terrestrial blend: Algal biomass produced in excess of conversion capacity is blended at an optimal or preferred ratio with terrestrial biomass, dried, and stored until conversion capacity becomes available.
}
Base case, algae only: Algal biomass produced in excess of conversion capacity is dried and stored until conversion capacity becomes available.

\subsection{Logistics and techno-economic analyses}

A logistics-based economic feasibility analysis was performed to compare the feedstock related costs of managing biomass produced in excess of the conversion capacity of an on-site HTL conversion facility. The analysis considered feedstock availability and distance (i.e. 
transportation costs) from a dedicated HTL conversion facility co-located with the algae production facilities. The variability in algal productivity at a given site was calculated using data derived from the Integrated Assessment Framework (IAF) [13]. The IAF analysis simulated the daily variability in biomass production over a 30 -year period using stochastic weather data [29] and algae growth models for a generic algal strain and a production strain (Chlorella sp. 1412), providing long-term, mean daily algal production across an array of sites. For this analysis, data for Chlorella at a theoretical site in Beaumont, TX was selected and is shown in Figure 2. This figure illustrates potential conversion capacities (dashed lines) and how they relate to average productivity throughout the year (Figure 2). Exceedence for a given conversion capacity is calculated from this data. Both scenarios included in the economic analysis are located in eastern Texas due to the co-location of pine and algae resources [13,30].

The base case scenario assumes wet algae begins with $80 \%$ moisture content (wb), which is then dried to a final moisture content of $10 \%(\mathrm{wb})$. For the algae blending scenario, pine contains $6 \%$ (wb) moisture, prior to blending; algae/pine blends are then dried to a final moisture content of $10 \%$ (wb) moisture. The cost for procuring (purchase and transport) pine material is included in the cost analysis of the algae blend scenario.

Energy consumption for drying was estimated based on vendor supplied dryer efficiencies and the calculated energy of water evaporation. A preliminary drying experiment found that a 40:60 blending ratio (on a dry weight basis) of algae/pine was found to perform well in the bench-scale dryer. To maintain this ratio, the blending scenario requires a dryer capacity of 3.3 tonne $\mathrm{hr}^{-1}$ and an energy consumption of $1205 \mathrm{kw} \mathrm{hr}$ tonne $^{-1}$. In the base case scenario, drying algae would require an energy consumption of $2954 \mathrm{kw} \mathrm{hr}$ tonne $^{-1}$ to reduce moisture content from $80 \%$ to $10 \%$ and requires a dryer capacity estimated at 1.4 tonne $\mathrm{hr}^{-1}$. Energy requirements for drying 
were incorporated into the Biomass Logistics Model (BLM) to estimate drying costs incurred in each scenario. The BLM was developed by the Idaho National Laboratory to estimate cost, economic, and environmental performance of operations involved in biomass logistics [31]. The BLM uses the Agricultural and Applied Economics Association (AAEA) methods and equations for its calculations [31]. A relevant equation for calculation can be found in supplementary material. For this analysis, the following information for rotary dryers (Table 1) was assumed for each scenario.

Table 1. Rotary Dryer specifications and economic parameters

\begin{tabular}{lc}
\hline Parameter & Assumption \\
\hline List price $(\$, 2011)$ & $\$ 905,000$ \\
\hline Installation factor & 1.6 \\
Fuel type & Natural gas \\
Fuel price $(\$, 2011 / \mathrm{MBTU})$ & $\$ 4.99$ \\
Useful life (hrs) & 168,000 \\
Energy of evaporation (BTU $\mathrm{lb}^{-1}$ & 1440 \\
$\left.\mathrm{H}_{2} \mathrm{O}\right)$ & \\
Dryer efficiency & $65 \%$ \\
Salvage value $(\%)$ & 30 \\
Repair and maintenance cost & 10 \\
(measured as \% of list price) & 18 \\
Weeks of operation & 24 \\
Daily hours of operation & $8 \%$ \\
Interest rate & \\
\hline
\end{tabular}

Feedstock related costs for each scenario considered the cost of pine, production of algae biomass, drying costs, storage costs, and the loss of revenue from idled equipment. Jacobson et al., 2014 reports the cost of delivered pulpwood at $\$ 109.66$ tonne $^{-1}$ for $9 \%$ moisture (wb). An additional $\$ 7.55$ tonne $\mathrm{e}^{-1}$ was assumed to account for the moisture reduction to $6 \%$ (wb), leading to a total delivered cost of $\$ 117.21$ tonne $^{-1}$ [32]. Algae feedstock cost was estimated at $\$ 474$ tonne $^{-1}$ [9]. Storage costs were assumed to be $\$ 4.60$ tonne $^{-1}$. HTL plant capacity was designed to 
$30 \%$ exceedence, calculated from IAF data for Beaumont, TX $\left(21 \mathrm{~g} \mathrm{~m}^{-2}\right.$ day $^{-1}$, or $28,066.50$ tonne $\mathrm{yr}^{-1}$ for a 405 ha farm) [13] (Table 2). Loss of revenue from idle processing capacity was calculated from HTL capacity shortage, expected fuel yield of 145 gallon gasoline equivalent (gge) tonne ${ }^{-1}$ algae (ash-free dry weight, AFDW) [9], and a fuel selling price of $\$ 3.00$ per gge. In this analysis, only the feedstock related costs required to deliver materials to the reactor throat were considered.

The ratio of algae to terrestrial biomass in a blend also has an impact on the energy content of the dried material. Given that algae has a higher energy content than lignocellulosic material (25-30 $\mathrm{MJ} / \mathrm{kg}$ vs. $12-20 \mathrm{MJ} / \mathrm{kg}$, [33]), algae could contribute anywhere from $45-63 \%$ of the total embodied energy. The difference in energy content of each material (algae and pine) impacts the amount of fuel that can be produced from each. For this study, it was assumed that a tonne of algae converted by HTL would yield 145 gge [9], while a tonne of pine would yield 71.5 [34].

Table 2: Input data used to estimate the annual cost of handling production variation under different scenarios.

\begin{tabular}{|c|c|c|c|c|}
\hline \multirow[b]{3}{*}{ Input parameter } & \multicolumn{4}{|c|}{ Scenario } \\
\hline & \multirow{2}{*}{$\begin{array}{l}\text { Algae Only } \\
\text { Base case }\end{array}$} & \multicolumn{3}{|c|}{ Algae blend } \\
\hline & & $\begin{array}{l}40 \% \text { Algae } \\
\text { Blend }\end{array}$ & $\begin{array}{l}30 \% \text { Algae } \\
\text { Blend }\end{array}$ & $\begin{array}{l}22 \% \text { Algae } \\
\text { Blend }\end{array}$ \\
\hline Algal biomass production (tonne $\mathrm{yr}^{-1}$ ) & 17,061 & 17,061 & 17,061 & 17,061 \\
\hline Exceedence production (tonne $\mathrm{yr}^{-1}$ ) & 2,447 & 2,447 & 2,447 & 2,447 \\
\hline Pine purchased (tonne $\mathrm{yr}^{-1}$ ) & - & 3671 & 5,710 & 8,559 \\
\hline Total material processed (tonne $\mathrm{yr}^{-1}$ ) & 19,508 & 23,179 & 25,218 & 28,067 \\
\hline HTL capacity (tonne $\mathrm{yr}^{-1}$ ) & 28,067 & 28,067 & 28,067 & 28,067 \\
\hline Total capacity shortage (tonne $\mathrm{yr}^{-1}$ ) & 8,559 & 4,888 & 2,849 & 0 \\
\hline
\end{tabular}

All material quantities listed on an ash-free dry weight basis

\section{Results and discussion}

3.1 Shear tests of blend materials 
Microalgal biomass dewatered to $20 \%$ solids was found to be a cohesive material that tends to agglomerate to surfaces and resists flowing. This is a challenge to effective drying, as commonly used dried dryers, such as rotary dryers, are most effective with free flowing materials. The many lifts within a rotary dryer continuously move material from the bottom of the dryer to the top where it is then showered through a hot gas stream. A cohesive material can stick to the lift surfaces and, consequently, does not pass through the hot gas stream, limiting the surface area exposed. As a result, cohesion makes drying algae in a rotary dryer very challenging. This paper describes an attempt to decrease cohesion in algal biomass by blending it with low moisture terrestrial biomass and thus improve drying efficiency.

Shear tests applied to three algae/pine blends (30\%, 40\%, and 50\% algae) were used to test their cohesive nature compared to unblended ground pine at $59 \%$ moisture. Shear tests were conducted using preshear compressive stress of approximately $9.3 \mathrm{kPa}$ to obtain yield locus curves for each material. Notably, material cohesion and unconfined yield stress $\left(f_{c}\right)$ increased with increasing algae content. Table 3 summarizes the flow properties of the samples, including standard deviations of the replicated measurements and indicates that the materials become more cohesive as the concentration of algae increases. The flowability of a material $\left(f f_{c}\right)$ is defined, generally, by the following scale [28]:

$$
\begin{aligned}
& 0<f f_{c}<2-\text { Very cohesive and non-flowing } \\
& 2<f f_{c}<4-\text { Cohesive } \\
& 4<f f_{c}<10-\text { Easy-flowing } \\
& 10<f f_{c}-\text { Free-flowing }
\end{aligned}
$$


Pine, used for blending with algae and re-moistened to $59 \%$ moisture (wb), had an $f f_{c}$ of 5 , ranking as an easy-flowing material. Algae blends with 50\% algae were determined to be very cohesive and non-flowing $\left(f f_{c}\right.$ of 1.8). Blends with $30 \%$ and $40 \%$ algae ranked in between these two extremes and were considered to be cohesive. A direct correlation between material shear strength and drying performance in a rotary dryer has not been established, so these results cannot be used directly to estimate drying performance. Rather, an understanding of material shear strength and wall friction properties can be used to design dryers with the required diameters and wall materials to ensure optimum flowability during the drying process. For example, because all of the shear tests were performed with similar values of major principal stress $\left(\sigma_{1} \approx 25 \mathrm{kPa}\right.$ ), the unconfined yield stress $f_{c}$ can be used as a measure of relative strength of resistance to flow. Table 3 indicates that $f_{c}$ nearly doubles from $4.8 \mathrm{kPa}$ to $8.7 \mathrm{kPa}$ as algae is blended into pine from $0 \%$ to $30 \%$ algae on a dry basis and nearly triples to $13.7 \mathrm{kPa}$ as algae is blended into pine at $50 \%$ on a dry basis. From an engineering perspective, these results indicate that the diameter of the rotary drum to dry a 50/50 pine/algae blend will need to be at least 3 times larger than the diameter of a rotary drum to dry finely ground pure pine. Considering that pine chips have been reported to be able to support arches in bins with openings as large as $5.2 \mathrm{~m}$ (17 ft) [35], it is apparent that drying pine/algae blends will require active agitation to mix the material and prevent large-scale particle agglomeration that inhibits drying.

Table 3. Summary of rheological properties obtained from a Schulze automated shear tester equipped with a size $\mathrm{S}$ shear cell.

\begin{tabular}{cccccc}
\hline Sample & $\sigma_{1}(\mathrm{kPa})$ & $f_{c}(\mathrm{kPa})$ & $f f_{c}(-)$ & $\delta\left(^{\circ}\right)$ & Cohesion $(\mathrm{kPa})$ \\
\hline 0\% Algae & $23.7 \pm 0.4$ & $4.8 \pm 0.4$ & $5.00 \pm 0.4$ & $42.4 \pm 0.3$ & $1.0 \pm 0.1$ \\
30\% Algae & $24.6 \pm 1.1$ & $8.7 \pm 0.4$ & $2.8 \pm 0.1$ & $45.6 \pm 1.0$ & $1.7 \pm 0.1$ \\
40\% Algae & $25.0 \pm 0.6$ & $10.5 \pm 0.1$ & $2.4 \pm 0.0$ & $46.4 \pm 0.1$ & $2.2 \pm 0.1$ \\
$50 \%$ Algae & $24.3 \pm 0.6$ & $13.7 \pm 1$ & $1.8 \pm 0.1$ & $48.2 \pm 1.0$ & $3.0 \pm 0.2$ \\
\hline$f f_{c}=\sigma_{1} / f_{c}$ \\
Numbers after “ \pm " indicate standard deviation of replicated measurements.
\end{tabular}


$\sigma_{\text {pre }}$ was equal to $9.3 \mathrm{kPa}$ for each measurement.

$\delta$ is the effective angle of internal friction.

\subsection{Thermogravimetric analysis}

Thermogravimetric analysis (TGA) was used to compare the drying rates of blends, as well as a pine and algae control. Drying curves, which plot the moisture ratio $\left(\mathrm{M}_{t} / \mathrm{M}_{i}\right)$ of each sample as a function of time (Figure 3), demonstrate the differences in drying between the materials. The $20 \%$ algae blend dried to approximately $0 \%$ moisture more quickly ( $1.7 \mathrm{hrs}$ ) than any other material, followed by the wet pine (1.86 hrs) and $40 \%$ algae blend (1.88 hrs), which had similar moisture contents (44\% and 47\% w.b., respectively) and dried in about the same amount of time. Samples containing greater than $60 \%$ (dry basis) algae took much longer to dry ( 2.4 hrs or more) (Figure 3). No differences in the drying curves of the $80 \%$ algae blend and $100 \%$ algae were apparent. Blending algae up to $40 \%$ with pine offers clear benefits to drying rates, whereas blends containing $60 \%$ or more algae offer no discernible benefit compared to drying algae alone. When comparing the drying rates of blends and the algae control, it is clear that drying rates are lower and materials are more hygroscopic with increasing algae content. Blends with $60 \%$ algae or less maintained high drying rates throughout the drying process relative to algae alone and the $80 \%$ algae blend (Figure 4); the drying rates of blends with $60 \%$ algae or less rapidly decreased as the sample reached dryness. In contrast, drying rates for $80 \%$ algae and algae only decreased in a linear fashion. Improved drying rates for blends were likely due to their increased surface area although this was not directly measured.

\subsection{Dryer studies}


Drying aids may be incorporated as a way to make the material less cohesive [34]. These aids can include organic polymers (e.g. maltodextrin), inorganic compounds (e.g. $\mathrm{CaCO}_{3}$ ), or fiber containing material (e.g. wheat bran) $[34,35]$. Results of these studies indicate that blending algae with terrestrial biomass, such as pine, acts like a drying aid; drying efficiency is increased through reduced cohesion and lower initial moisture contents. Rheology studies and TGA analysis from this study indicate that algae/biomass blends become less cohesive with decreasing algae content and dry more quickly than algae alone.

The blends in the drying study had notable differences in appearance and consistency, with blends becoming more cohesive and less free flowing with increasing algae content (Figure 5a). The consistency of the $80 \%$ blend appeared very similar to the algae starting material, while the $40 \%$ algae blend appeared to have discrete particles like the pine starting material. The $80 \%$ algae blend and $100 \%$ algae dried very poorly, decreasing in moisture content by only $10 \%$ in the time that it took the 40 and $60 \%$ blends to reach less than $10 \%$ total moisture (Supplementary Figure 2).

The amount of algae included in the blend had a strong influence on both the drying rate and the appearance of the final product. The $40 \%$ and $60 \%$ algae blends both dried to stability over the course of the experiment $(<10 \%)$, yet the dried blended material differed from one another in their physical appearance (Figure 5b). The $60 \%$ blend agglomerated to large egg-shaped masses, approximately $4 \mathrm{~cm}$ in diameter, that were strong and resistant to breakage, while the $40 \%$ blend dried as small discrete particles with a few weak clumps that broke apart with slight pressure. The $80 \%$ algae blend and $100 \%$ algae control failed to dry because it formed a thick paste-like coating on the interior surface of the drum, stable enough to support the growth of a mat of filamentous fungi while rotating. It was apparent from both the drying curves and the condition 
of the final material that algae only and algae blends with as much as $80 \%$ algae were not suitable for drying in a rotary drum dryer. The $60 \%$ algae blend reached the target moisture content of $10 \%$ in a time frame comparable to the $40 \%$ blend, but the final material formed large clumps that were difficult to break. The strong, irregular-sized clumps are not ideal for downstream conversion processes and may necessitate an additional comminution step to achieve a uniform particle size distribution suitable for downstream processing.

Because blends with $40 \%$ algae resulted in a final product with small particle sizes but $60 \%$ algae blends did not, follow up experiments sought to further characterize the drying rates of blends containing less than 50\% algae. Algae/pine blends containing 30\% and 50\% algae were included in the second study along with the $40 \%$ algae blend and pine (59\% moisture, wb) and algae only controls. As before, algae/pine blends, prior to drying, were less cohesive with increasing pine content. The wet $30 \%$ and $40 \%$ algae blends appeared more like unblended pine, having discrete particles (Figure 6a). The wet blend containing 50\% algae aggregated, forming many small ( $2 \mathrm{~cm}$ diameter) clumps, whereas, blends with $60 \%$ and $80 \%$ algae, from the preliminary drying study, formed one cohesive mass.

The change in moisture content of each drum was measured gravimetrically over the course of the experiment until the weight of each drum became constant. The $30 \%$ and $40 \%$ algae blends reached a moisture content of $<10 \%$ within 24 hours (Figure 7 ). After 40 hours of drying, the $50 \%$ blend reached the same point. Unlike in the preliminary study, the algae only control was able to reach $<10 \%$ moisture, but required 110 hours of drying to do so. The drying curve for the wet pine (59\% initial moisture content) control was very similar to the $40 \%$ algae blend, reaching $11 \%$ moisture after 24 hours. Despite having a higher moisture content (59\%, wb), the wet pine dried more quickly than the $50 \%$ algae blend with an initial moisture content of $54 \%$ (wb). The 
observed differences in these two materials may be an artifact of the rewetting process. The soak method used to bring the pine moisture content to $59 \%$ (wb) may not be representative of moisture contained within living cells. This may account for the observed difference in drying time with the algae blend taking longer to dry, despite having less moisture.

The consistency of the dried 30\% and 40\% algae blends was similar to the dried pine control with discrete small particles, as was observed in the preliminary experiment for the $40 \%$ blend. The dried 50\% algae blend had, not surprisingly, a consistency that was intermediate to $40 \%$ blends and the $60 \%$ blend, forming numerous small ( 1-2 cm diameter) pebble shaped clumps, which retained their shape after applying moderate pressure (visible in Figure 6b). After 40 hours of drying, the algae only drum retained $45 \%$ of its initial moisture content, at which point the drum lid was removed to inspect the material. As in the initial study, the algae biomass lined the perimeter of the drum as a thick paste. The algae drum was returned to the incubator for another 80 hours until dry. The algae dried as a hard, irregularly-shaped material with a wide particle size distribution that included small chunks ( $\sim \mathrm{mm}$ diameter) and long (up to $10 \mathrm{~cm}$ and $1 \mathrm{~cm}$ deep) flat pieces. If this drying approach was adopted for algae preservation in a full-scale operation, a comminution step may be necessary to reduce the material to a uniform size for optimal conversion, as the dried particle size distribution is substantially different from fresh algae, the usual feed material for HTL or other approaches to algae processing.

The blending approach to achieve more efficient drying could have broader utility if multiple feedstocks could achieve the same results as pine when blended with algae, extending this approach to areas where pine may not be readily available and preserving algae for end uses other than HTL. Sorghum, an energy crop, and corn stover are two potential feedstocks that are available when algae production is peaking and are considered feedstocks for biochemical 
conversion to biofuels and bioproducts $[38,39]$. At the time of harvest, both sorghum and corn stover have a higher moisture content than the pine used for this study $(78.5 \%$ and $46.6 \% \mathrm{wb}$, respectively) and were used "field-delivered" and dried (6.5\% and 8.0\%, wb, respectively) for blending and drying studies at a ratio of 40:60, algae/biomass (Figure 7B). The algae blended with "field-delivered" sorghum had a moisture content of $80.9 \%$ (wb), the highest moisture content of any blend tested. As a consequence, the algae/sorghum blend drying curves resembled that of algae alone. Direct-from-field corn stover blends also had high initial moisture content $(71.4 \%, w b)$ and dried slowly as well. The algae blends with either dry sorghum or dry corn stover (66\% and $67.7 \%$ moisture, wb, respectively) reached $<10 \%$ moisture in half the time as direct-from-field corn stover. Interestingly, the drying curves for both dry sorghum and corn stover were identical. The time to reach dryness for each of the dry feedstocks was significantly longer than algae/pine blends with $40 \%$ algae. This can be explained by the difference in moisture content of the algae used in each blend. Pine was blended with algae with an initial moisture content of $71.5 \%$, while sorghum and corn stover were blended with a different batch of algae with higher moisture $(83.4 \%)$.

The effect that moisture content has on drying rates is intuitive; more moisture will require more energy for removal. This result raises the question as to whether drying rate enhancement achieved by blending is due solely to reduction in moisture content or whether the blend material has an effect, such as reduction in cohesion observed for algae/pine blends. Sand was chosen as an inert material that could be added to reduce moisture content but possesses none of the properties of lignocellulosic biomass. When blended with sand at the 40:60 ratio (algae:sand), the appearance and consistency of the blend was no different than algae alone. The drying curve for the sand blend (65.8\% moisture, wb) for the first 15 hours was identical to the dry sorghum 
and corn stover blends (Figure 7B). However, beyond 15 hours the drying rate for the sand blend slowed substantially. When dry sorghum and corn stover blends reached $<10 \%$ of the initial moisture, the sand blend retained $35 \%$ of the initial moisture content despite starting with less moisture, indicating that both sorghum and corn stover imparted properties to each blend that enhanced drying rates.

Although preserving biomass for HTL conversion has been the focus of this study, a similar approach could be taken to manage exceedence for other conversion pathways, such as combined algal processing (CAP) [26]. This approach to conversion combines a fermentation to produce fuel intermediates from proteins and carbohydrates followed by lipid extraction and upgrading. The use of terrestrial biomass to enable drying and storage introduces material that may not contribute to final fuel yields in the CAP process as it does for HTL conversion. To accommodate this conversion pathway and others not compatible with terrestrial biomass, drying in a rotary drum dryer could be achieved by back mixing dried algae biomass with fresh biomass to reduce the initial moisture content and improve flowability. The initial dry material for back mixing could be produced by blending with terrestrial biomass. Blending dry algae with fresh algae at a 40:60 ratio of fresh algae paste ( $83.4 \%$ moisture, wb) with dry algae (<10\% moisture) resulted in a moisture content of $67.5 \%(\mathrm{wb})$, which resulted in initial drying rates comparable to that observed for either dry corn stover or dry sorghum (Figure 7B). This initial drying rate enhancement was primarily achieved as a result of the reduced moisture content as the blend of fresh and dry algae, when blended, had a consistency similar to modeling clay as opposed to the discrete particles of blends with terrestrial feedstocks. Therefore, as the fresh/dry algae blend reached $30 \%$ remaining moisture the drying rate began to slow, whereas algae blends with either dry corn stover or dry sorghum continued to dry at the same rate until less than $10 \%$ of the initial 
moisture remained. These differences suggests that a reduced moisture content is not the only parameter of importance in achieving effective drying of algae blends, but that the physical structure of terrestrial biomass aids effective drying to $<10 \%$ moisture (wb).The algae strain used in this study, Scendesmus sp., is considered by many to be a good candidate for biofuel production. There are, however, many other industrially relevant strains that differ from one another in biochemical composition, size, and shape. This study did not examine how different strains might affect drying efficiency when blended with terrestrial biomass. Our results show that moisture content and the presence of lignocellulosic biomass significantly affect drying rates. Differences in biochemical composition are not likely to have as large an effect and may require an adjustment to the algae/terrestrial biomass blend ratio for optimal drying.

The drying studies conducted here indicate that algae biomass dries at a higher rate than algae alone when blended at an optimal ratio with terrestrial biomass and at a rate comparable to terrestrial biomass of similar moisture content, as seen in the case of pine. The optimal ratio will depend on the moisture content of both the algae biomass and the terrestrial biomass. In addition to improved drying rates, the blending approach results in a more uniformly dried algal product that would likely result in improved conversion efficiency compared to algae dried alone. Drying algae-terrestrial biomass blends offers a technically feasible approach to managing algae biomass exceedence during summer months for winter conversion.

\subsection{Logistics and economic analysis}

Algae blended with terrestrial biomass offers technical advantages to drying algae alone; however, the question remains whether the blending approach is cost-competitive. A technoeconomic analysis was used to compare the feedstock related costs of blending algae with terrestrial biomass to the base case of drying algae directly. The economic analysis considered 
the cost of algae production, procurement of pine for blending, cost of drying and storing algae, and lost revenue due to underutilized conversion capacity.

The economic analysis relies on modeled Chlorella biomass production and an analysis of economically scaled downstream algal production facilities to determine exceedence - algae biomass produced in excess of conversion capacity - and production shortages [13]. Seasonal variability can amount to a 10:1 difference in summer and winter production. Coleman et al. have modeled the expected biomass production at 4,460 sites within the U.S. based upon an algae growth model that incorporated water temperature constraints, optimal temperature ranges for growth, and light saturation. Key to the growth model was the development of a 30-year meteorological database of hourly values for precipitation, insolation, temperature, relative humidity and water temperature [29]. The growth model utilized this meteorological database to model hourly-aggregated daily averages of biomass production over a 30 year period. Utilizing this approach, the daily and annual variability in algae biomass production is accounted for in the economic model. For the purpose of this study, the daily average of biomass yields from the Beaumont, TX site were used. This site is located in the gulf region with plentiful resources for algae growth and is proximal to pine resources. Figure 8 relates the variability in daily algae production at the selected site, averaged over 30 years, to the conversion capacity over the course of the year; seasonal variations are apparent. At times, production exceeds conversion capacity while feedstock shortages occur periodically. The exceedence in each scenario being considered amounts to 2,447 tonnes annually, while each year the feedstock shortfall is 11,006 tonnes, a net shortage of 8,559 tonnes for the base case scenario.

Drying cost for algae blend and algae only scenarios is estimated at $\$ 43.11$ tonne ${ }^{-1}$ and $\$ 106.54$ tonne $^{-1}$ respectively. The unit ownership and operation cost for drying in both the algae blend 
and algae only scenarios are significantly different (Table 4). Drying efficiency and fuel costs are major contributors to the overall cost; a decrease in the cost of natural gas from $\$ 4.99$ to $\$ 3.99$ would result in a $10 \%$ reduction in drying cost $(\$ 4.11$ and $\$ 10.06)$.

Table 4: Estimation of drying cost (in 2011 \$) in algae blend (40\% algae blend) and algae only scenarios

\begin{tabular}{lcc}
\hline Cost $\left(\$\right.$ dry tonne $\left.{ }^{-1}\right)$ & $\begin{array}{c}\text { Algae Blend } \\
\left(\$ \text { dry tonne }^{-1}\right)\end{array}$ & $\begin{array}{c}\text { Algae Only } \\
\left(\$ \text { dry tonne }^{-1}\right)\end{array}$ \\
\hline Ownership costs & & \\
$\quad$ Interest and depreciation & 17.06 & 42.63 \\
$\quad$ Insurance, Housing, and Taxes (IH\&T) & 3.12 & 7.81 \\
Operating costs & & \\
$\quad$ Repair \& maintenance ( R\&M) & 0.65 & 1.56 \\
Fuel & 20.52 & 50.31 \\
$\quad$ Labor & 1.76 & 4.23 \\
\hline Total & 43.11 & 106.54 \\
\hline
\end{tabular}

In the algae blend and algae only scenarios feedstock shortages occurring in the winter are not completely covered by algae or algae blends stored during the summer, resulting in a feedstock shortage and an HTL facility operating below capacity. As the algae blend scenarios utilize pine to enhance dryer performance, feedstock shortages are partially or completely made up by the additional terrestrial biomass, resulting in a lower annual shortage than the base case $(4,888$ vs. 8,559 tonnes, Table 2). Given the satisfactory performance of dryers with any blend containing $40 \%$ algae or less, algae/pine blend ratios could be adjusted to eliminate conversion capacity shortages. Capacity shortages are eliminated when excess algae is blended with pine at a ratio of $22 \%$ algae (dry basis) prior to drying (Table 5).

Blending algae produced in excess of conversion capacity with terrestrial biomass (e.g. pine) offers an economic benefit (Table 5). In each scenario the dominant contributor to feedstock related costs was algal biomass production. Therefore, the total cost of algae biomass production 
is the same (\$474 tonne $\left.\mathrm{e}^{-1},[9,11]\right)$ but differs on a per gge basis as the blend scenarios result in more fuel produced. The blending approach reduces the per gallon cost of drying excess algae from $\$ 0.092$ to $\$ 0.076$ because of increased efficiency in drying. The cost of pine for blend scenario (22\% algae) contributes an additional \$ 0.29 per gge, but this is outweighed by the ability to operate at maximum capacity, producing the maximum amount of fuel possible. As a consequence of operating the conversion facility below maximum capacity due to insufficient feedstock, the algae only scenario forgoes as much as $\$ 1.32$ per gge in potential revenue.

Utilizing algae/pine blends with $22 \%$ algae eliminates feedstock shortage at the conversion facility and reduces feedstock related costs from $\$ 4.68$ (base case) to $\$ 3.07$ per gge of fuel. The blending approach highlights the importance of not allowing the conversion facility to operate below full capacity due to feedstock shortage.

Table 5: Feedstock related costs $\left(\$ g_{g e}{ }^{-1}\right)$ of handling production variation under each scenario

\begin{tabular}{|c|c|c|c|c|}
\hline \multirow{3}{*}{$\begin{array}{l}\text { Cost Parameter } \\
\left(\$ g g e^{-1}\right)\end{array}$} & \multicolumn{4}{|c|}{ Scenario } \\
\hline & \multicolumn{3}{|c|}{ Algae Blend } & \multirow{2}{*}{$\begin{array}{c}\text { Algae only } \\
\text { Base case }\end{array}$} \\
\hline & $22 \%$ Algae & $30 \%$ Algae & $40 \%$ Algae & \\
\hline Algae feedstock ${ }^{b}$ & 2.69 & 2.86 & 2.99 & 3.27 \\
\hline Drying cost & 0.076 & 0.081 & 0.085 & 0.092 \\
\hline Cost of Pine ${ }^{c}$ & 0.29 & 0.21 & 0.14 & \\
\hline Storage costs ${ }^{\mathrm{d}}$ & 0.013 & 0.011 & 0.008 & 0.004 \\
\hline Loss of Revenue & 0.00 & 0.38 & 0.69 & 1.32 \\
\hline Total & 3.07 & 3.54 & 3.91 & 4.68 \\
\hline \multicolumn{5}{|c|}{$\begin{array}{l}{ }^{\text {a }} \text { Total cost for each parameter/gge produced. Fuel yields of } 145 \text { gge tonne }^{-1} \\
\text { (AFDW) [9] and } 71.5 \text { gge tonne }{ }^{-1} \text { [34] were assumed for algae and pine } \\
\text { respectively. } \\
{ }^{\text {b } \$ 474 \text { tonne }}{ }^{-1} \text { (AFDW) } \\
{ }^{\mathrm{c}} \$ 117.21 \text { tonne } \mathrm{e}^{-1} \\
{ }^{\mathrm{d}} \$ 4.60 \text { tonne }{ }^{-1} \text { dried material } \\
{ }^{\mathrm{e}} \text { Based on capacity shortage, anticipated HTL yield of } 145 \text { gge tonne }^{-1} \text {, and a } \\
\text { selling price of } \$ 3.00 \text { per gge. }\end{array}$} \\
\hline
\end{tabular}

This study addresses one approach to maximizing the fuel yield from a given algae farm with onsite HTL facilities by drying algae blended with lignocellulosic feedstock. The success of this approach will depend on the co-location of both algae and terrestrial feedstock resources. In 
areas where terrestrial feedstocks are limited and the climate is ideal for algae growth, an alternative approach to maintaining conversion facilities at capacity could be taken, where HTL conversion facilities are built to accommodate maximum summer algae production. During the rest of the year, conversion capacity could be maintained with wet-waste feedstocks sourced or generated from municipal solid waste, solids from wastewater treatment, and carbon rich waste

streams from food processing [40-42]. This approach will require larger capital investments and, without on-site feedstock storage, assumes greater feedstock risks. A comparison of the two approaches was not undertaken in this work, and the more economical of the two is likely to be site-specific.

The economic analysis does not include the cost to convert feedstock to fuel as in the $2014 \mathrm{HTL}$ design case [9]. Instead, this paper focuses on efficient utilization for the feedstock side of the logistics supply chain. Conversely, The HTL design case does not specifically assign a cost to the loss of revenue or potential earnings due to insufficient materials, which this economic analysis has captured in order to compare two different operating scenarios. The HTL design case evaluated the impact of utilizing the full conversion capacity through a different approach and determined that a cost reduction of $12.5 \%$ could be achieved [9]. HTL plants are significant capital investments, and it is important to explore maximum utilization potential by augmenting insufficient material streams to provide predictable, reliable feedstocks for conversion, which could be easily achieved through creative strategies as this paper has demonstrated.

\section{Conclusion}

Algae biomass productivity is highly variable; summer production can be as much as ten times higher than in the winter. The difference in seasonal production creates a challenge to optimally scale downstream conversion facilities. Algae biomass cultivation is the largest contributor to the 
cost of fuel production from algae, comprising $74 \%$ of the total cost. The challenge is to capture all of the algae biomass for fuel production while maintaining conversion facilities at full capacity. The approach detailed in this study, algae blended with terrestrial biomass, enables the use of high throughput rotary dryers, incapable of drying algae directly, to preserve excess algae for use during the off season. Blending algae with terrestrial biomass results in lower drying costs and adjustment of the blend ratio can be used as a management tool to ensure conversion facilities operate at full capacity.

\section{Acknowledgements}

We gratefully acknowledge Prof. Bruce Bugbee (Utah State University, Logan, UT) and Dr. Thomas Dempster (AzCATI, Arizona State University, Mesa, AZ) for providing large quantities of high quality algal biomass. This work was supported by Bioenergy Technologies Office (BETO) within the Energy Efficiency and Renewable Energy Office of the U.S. Department of Energy under Idaho Operations Office Contract No. DE-AC07-05ID14517.

\section{References}

[1] P.J. le B. Williams, L.M.L. Laurens, Microalgae as biodiesel \& biomass feedstocks: Review \& analysis of the biochemistry, energetics \& economics, Energy Environ. Sci. 3 (2010) 554. doi:10.1039/b924978h.

[2] Q. Hu, M. Sommerfeld, E. Jarvis, M. Ghirardi, M. Posewitz, M. Seibert, A. Darzins, Microalgal triacylglycerols as feedstocks for biofuel production: perspectives and advances, Plant J. 54 (2008) 621-639. doi:10.1111/j.1365-313X.2008.03492.x.

[3] P. Neofotis, A. Huang, K. Sury, W. Chang, F. Joseph, A. Gabr, S. Twary, W. Qiu, O. Holguin, J.E. Polle, Characterization and classification of highly productive microalgae strains discovered for biofuel and bioproduct generation, Algal Res. 15 (2016) 164-178. 
[4] C. Adams, V. Godfrey, B. Wahlen, L. Seefeldt, B. Bugbee, Understanding precision nitrogen stress to optimize the growth and lipid content tradeoff in oleaginous green microalgae, Bioresour. Technol. 131 (2013) 188-194. doi:10.1016/j.biortech.2012.12.143.

[5] N. Uduman, Y. Qi, M.K. Danquah, G.M. Forde, A. Hoadley, Dewatering of microalgal cultures: A major bottleneck to algae-based fuels, J. Renew. Sustain. Energy. 2 (2010) 12701. doi:10.1063/1.3294480.

[6] B.D. Wahlen, R.M. Willis, L.C. Seefeldt, Biodiesel production by simultaneous extraction and conversion of total lipids from microalgae, cyanobacteria, and wild mixed-cultures, Bioresour. Technol. 102 (2011) 2724-2730. doi:10.1016/j.biortech.2010.11.026.

[7] B.D. Wahlen, M.R. Morgan, A.T. McCurdy, R.M. Willis, M.D. Morgan, D.J. Dye, B. Bugbee, B.D. Wood, L.C. Seefeldt, Biodiesel from microalgae, yeast, and bacteria: engine performance and exhaust emissions, Energy Fuels. 27 (2013) 220-228. doi:10.1021/ef3012382.

[8] R. Davis, A. Aden, P.T. Pienkos, Techno-economic analysis of autotrophic microalgae for fuel production, Appl. Energy. 88 (2011) 3524-3531. doi:10.1016/j.apenergy.2011.04.018.

[9] S. Jones, R. Davis, Y. Zhu, C. Kinchin, D. Anderson, R. Hallen, D. Elliott, A. Schmidt, K. Albrecht, T. Hart, others, Process design and economics for the conversion of algal biomass to hydrocarbons: Whole algae hydrothermal liquefaction and upgrading, Dep. Energy Bioenergy Technol. Off. US. (2014). https://hydrogen.gov/bioenergy/pdfs/pnnl_whole_algae_liquefaction.pdf (accessed November 11, 2014).

[10] J.C. Quinn, R. Davis, The potentials and challenges of algae based biofuels: A review of the technoeconomic, life cycle, and resource assessment modeling, Bioresour. Technol. 184 (2015) 444-452. doi:10.1016/j.biortech.2014.10.075.

[11] R. Davis, C. Kinchin, J. Markham, E.C.D. Tan, L.M.L. Laurens, D. Sexton, D. Knorr, P. Schoen, J. Lukas, Process design and economics for the conversion of algal biomass to biofuels: algal biomass 
fractionation to lipid- and carbohydrate-derived fuel products, (2014).

http://www.nrel.gov/docs/fy14osti/62368.pdf (accessed February 1, 2016).

[12] R. Davis, J. Markham, C. Kinchin, N. Grundl, E.C. Tan, D. Humbird, Process design and economics for the production of algal biomass: Algal biomass production in open pond, 2016. http://www.nrel.gov/docs/fy16osti/64772.pdf (accessed March 15, 2016).

[13] A.M. Coleman, J.M. Abodeely, R.L. Skaggs, W.A. Moeglein, D.T. Newby, E.R. Venteris, M.S. Wigmosta, An integrated assessment of location-dependent scaling for microalgae biofuel production facilities, Algal Res. 5 (2014) 79-94. doi:10.1016/j.algal.2014.05.008.

[14] L.M. Wendt, B.D. Wahlen, Unpublished data, (n.d.).

[15] J.R. Hess, K.L. Kenney, L.P. Ovard, E.M. Searcy, C.T. Wright, Commodity-scale production of an infastructure-compatible bulk solid from herbaceous lignocellulosic biomass, Idaho National Laboratory, 2009. https://bioenergy.inl.gov/Reports/Uniform\%20Format\%20Bioenergy\%20Feedstock.pdf (accessed March 3, 2016).

[16] J.J. Milledge, S. Heaven, A review of the harvesting of micro-algae for biofuel production, Rev. Environ. Sci. Biotechnol. 12 (2013) 165-178. doi:10.1007/s11157-012-9301-z.

[17] K.-Y. Show, D.-J. Lee, A.S. Mujumdar, Advances and challenges on algae harvesting and drying, Dry. Technol. 33 (2015) 386-394. doi:10.1080/07373937.2014.948554.

[18] C.-L. Chen, J.-S. Chang, D.-J. Lee, Dewatering and drying methods for microalgae, Dry. Technol. 33 (2015) 443-454. doi:10.1080/07373937.2014.997881.

[19] M.A. Delele, F. Weigler, J. Mellmann, Advances in the application of a rotary dryer for drying of agricultural products: a review, Dry. Technol. 33 (2015) 541-558. doi:10.1080/07373937.2014.958498. 
[20] E.P. Bennion, D.M. Ginosar, J. Moses, F. Agblevor, J.C. Quinn, Lifecycle assessment of microalgae to biofuel: Comparison of thermochemical processing pathways, Appl. Energy. 154 (2015) 10621071. doi:10.1016/j.apenergy.2014.12.009.

[21] T. Kudra, Sticky Region in Drying-Definition and Identification, Dry. Technol. 21 (2003) 14571469. doi:10.1081/DRT-120024678.

[22] A.R. Celma, S. Rojas, F. López, I. Montero, T. Miranda, Thin-layer drying behaviour of sludge of olive oil extraction, J. Food Eng. 80 (2007) 1261-1271. doi:10.1016/j.jfoodeng.2006.09.020.

[23] L. Bennamoun, P. Arlabosse, A. Léonard, Review on fundamental aspect of application of drying process to wastewater sludge, Renew. Sustain. Energy Rev. 28 (2013) 29-43. doi:10.1016/j.rser.2013.07.043.

[24] R. Arjona, P. Ollero, F. Vidal B., Automation of an olive waste industrial rotary dryer, J. Food Eng. 68 (2005) 239-247. doi:10.1016/j.jfoodeng.2004.05.049.

[25] Personal communication with representatives of Baker-Rullman, (n.d.).

[26] T. Dong, E.P. Knoshaug, R. Davis, L.M.L. Laurens, S. Van Wychen, P.T. Pienkos, N. Nagle, Combined algal processing: A novel integrated biorefinery process to produce algal biofuels and bioproducts, Algal Res. (2016). doi:10.1016/j.algal.2015.12.021.

[27] H.C. Bold, The morphology of Chlamydomonas chlamydogama, Sp. Nov., Bull. Torrey Bot. Club. 76 (1949) 101-108. doi:10.2307/2482218.

[28] D. Schulze, Powders and bulk solids: Behavior, characterization, storage, and flow, Springer Berlin Heidelberg, 2008.

[29] M.S. Wigmosta, A.M. Coleman, R.J. Skaggs, M.H. Huesemann, L.J. Lane, National microalgae biofuel production potential and resource demand, Water Resour. Res. 47 (2011) W0OHO4. doi:10.1029/2010WR009966. 
[30] R.D. Perlack, L.M. Eaton, A.F. Turhollow Jr, M.H. Langholtz, C.C. Brandt, M.E. Downing, R.L. Graham, L.L. Wright, J.M. Kavkewitz, A.M. Shamey, US billion-ton update: biomass supply for a bioenergy and bioproducts industry, Oak Ridge National Laboratory, Oak Ridge, TN, 2011.

[31] K.G. Cafferty, D.J. Muth, J.J. Jacobson, K.M. Bryden, Model based biomass system design of feedstock supply systems for bioenergy production, in: ASME 2013 Int. Des. Eng. Tech. Conf. Comput. Inf. Eng. Conf., American Society of Mechanical Engineers, 2013: p. V02BT02A023V02BT02A023.

http://proceedings.asmedigitalcollection.asme.org/proceeding.aspx?articleid=1830268 (accessed March 10, 2016).

[32] J.J. Jacobson, R.S. Mohammad, K.G. Cafferty, K.L. Kenney, E.M. Searcy, J. Hansen, Feedstock Supply System Design and Analysis, Idaho National Laboratory, Idaho Falls, ID, 2014. https://inldigitallibrary.inl.gov/sti/6308219.pdf (accessed March 10, 2016).

[33] D.C. Elliott, P. Biller, A.B. Ross, A.J. Schmidt, S.B. Jones, Hydrothermal liquefaction of biomass: Developments from batch to continuous process, Bioresour. Technol. 178 (2015) 147-156. doi:10.1016/j.biortech.2014.09.132.

[34] Y. Zhu, M.J. Biddy, S.B. Jones, D.C. Elliott, A.J. Schmidt, Techno-economic analysis of liquid fuel production from woody biomass via hydrothermal liquefaction (HTL) and upgrading, Appl. Energy. 129 (2014) 384-394. doi:10.1016/j.apenergy.2014.03.053.

[35] J. Johanson, Bin and Feeder Design for Wood Chips and Other Springy Bulk Solids", in: 1989. http://www.diamondbacktechnology.com/Articles-and-Papers.html (accessed April 20, 2016).

[36] M. Benali, M. Amazouz, Effect of drying-aid agents on processing of sticky materials, Dev. Chem. Eng. Miner. Process. 10 (2002) 401-414. 
[37] D.M. Cano-Higuita, H.A. Villa-Vélez, J. Telis-Romero, H.A. Váquiro, V.R.N. Telis, Influence of alternative drying aids on water sorption of spray dried mango mix powders: A thermodynamic approach, Food Bioprod. Process. 93 (2015) 19-28. doi:10.1016/j.fbp.2013.10.005.

[38] P. Alvira, E. Tomás-Pejó, M. Ballesteros, M.J. Negro, Pretreatment technologies for an efficient bioethanol production process based on enzymatic hydrolysis: A review, Spec. Issue Lignocellul. Bioethanol Curr. Status Perspect. 101 (2010) 4851-4861. doi:10.1016/j.biortech.2009.11.093.

[39] W.L. Rooney, J. Blumenthal, B. Bean, J.E. Mullet, Designing sorghum as a dedicated bioenergy feedstock, Biofuels Bioprod. Biorefining. 1 (2007) 147-157. doi:10.1002/bbb.15.

[40] H.M. Summers, R.N. Ledbetter, A.T. McCurdy, M.R. Morgan, L.C. Seefeldt, U. Jena, S. Kent Hoekman, J.C. Quinn, Techno-economic feasibility and life cycle assessment of dairy effluent to renewable diesel via hydrothermal liquefaction, Bioresour. Technol. 196 (2015) 431-440. doi:10.1016/j.biortech.2015.07.077.

[41] C. Drennan, Challenges and opportunities for wet-waste feedstocks - resource assessment., (2015). http://www.energy.gov/sites/prod/files/2015/07/f24/drennan_bioenergy_2015.pdf (accessed November 1, 2016).

[42] L.J. Snowden-Swan, R.T. Hallen, Y. Zhu, J.M. Billing, S.B. Jones, T.R. Hart, D.C. Elliott, S.P. Fox, Hydrothermal liquefaction and upgrading of municipal wastewater treatment plant sludge: a preliminary techno-economic analysis, Pacific Northwest National Laboratory (PNNL), Richland, WA (US), 2016. http://www.pnnl.gov/main/publications/external/technical_reports/PNNL25464Rev1.pdf (accessed November 1, 2016).

[43] W.J. Coumans, Models for drying kinetics based on drying curves of slabs, Chem. Eng. Process. Process Intensif. 39 (2000) 53-68. 


\section{Figures}

Figure 1. Schematic diagrams depicting two scenarios addressing variability in algal production to be used in techno-economic analysis: (Top) Algae blended with pine - biomass produced in excess of conversion capacity is first blended with pine (terrestrial biomass) prior to preservation by drying, (bottom) Algae dried alone (base case) - excess algal biomass is preserved for winter conversion by drying algae alone

Figure 2. Daily variability in Chlorella algal biomass production at a site in Beaumont, Tx, adapted from Coleman et al. [13]. 30 year average daily growth rates of Chlorella are plotted for a 350 day production season (blue line). Maximum (upper, green line) and minimum (lower, red line) algae production values are also plotted. Conversion facilities designed to (A) max capacity $\left(35 \mathrm{~g} \mathrm{~m}^{-2} \mathrm{day}^{-1}\right)$, (B) $10 \%$ exceedence $\left(30 \mathrm{~g} \mathrm{~m}^{-2}\right.$ day $\left.^{-1}\right)$, (C) $20 \%$ exceedence $\left(25.5 \mathrm{~g} \mathrm{~m}^{-2}\right.$ day $\left.^{-1}\right)$, and (D) $30 \%$ exceedence $\left(21 \mathrm{~g} \mathrm{~m}^{-2} \mathrm{day}^{-1}\right)$ are depicted by horizontal dashed lines. When algae production is higher than these capacities an exceedence occurs

Figure 3. Thermogravimetric analysis of algae/pine blends demonstrating the effect on drying curves that result from varying algae content. The moisture ratio $\left(\mathrm{M}_{t} / \mathrm{M}_{i}\right)$ is plotted against time for several different algae/pine blends (20\% algae $\boldsymbol{\Delta}$, $40 \%$ algae $\mathbf{\square}, 60 \%$ algae $\downarrow$, and $80 \%$ algae $\boldsymbol{\nabla})$ along with controls of pine $\left(\bullet, 44 \%\right.$ moisture, wb) and algae only $(\bullet) . \mathrm{M}_{t}$ is the moisture content (wet basis) at any time $t$ and $\mathrm{M}_{i}$ is the initial moisture content (wet basis). Percentage of algae in each blend is calculated on a dry solids basis. An equal amount of dry material from each blend was analyzed in triplicate.

Figure 4. The effect of varying algae/pine blend ratios on drying rate. The rate of water loss is plotted against the moisture content ( $g$ water $\mathrm{g}^{-1}$ dry solids) for multiple ratios of algae/pine 
blends including: $20 \%$ algae $\boldsymbol{\Lambda}, 40 \%$ algae $\mathbf{\square}, 60 \%$ algae $\downarrow$, and $80 \%$ algae $\boldsymbol{\nabla}$; and controls of pine $(\bullet, 44 \%$ moisture, wb) and algae only $(\bullet)$. An equal amount of material, on a dry matter basis, from each blend was analyzed in triplicate. Drying rates recorded during initial temperature ramp to $107^{\circ} \mathrm{C}$ were excluded from graph. Dotted line indicates increasing hygroscopicity among materials [43].

Figure 5. Appearance of materials from the preliminary drum dryer experiments (from left to right of both image $\mathrm{A}$ and $\mathrm{B}$, pine only, 40\%, 60\%, 80\% algae/pine blends, and $100 \%$ algae). Blends of a given algae/biomass ratio were calculated on a dry matter basis. Each drum was filled with $300 \mathrm{~g}$ of material on a dry matter basis. A) Blends and controls before rotation and incubation at $50^{\circ} \mathrm{C}$. B) Materials after 185 hours of incubation at $50^{\circ} \mathrm{C}$ and constant rotation.

Figure 6. Appearance of materials from second drum dryer experiment (from left to right of both image A and B, pine only, 30\%, 40\%, 50\% algae/pine blends, and 100\% algae). Blends of a given algae/biomass ratio were calculated on a dry matter basis. Each drum was filled with $150 \mathrm{~g}$ of material on a dry matter basis. A) Blends and controls before rotation and incubation at $50^{\circ} \mathrm{C}$. B) Materials after 41 hours of incubation and continuous rotation. Algae only drum was incubated for an additional 72 hours after this photo was taken.

Figure 7. Drying curves of algae blends and algae alone in bench-top rotary dryers. The moisture ratio $\left(M_{t} / M_{i}\right)$ is plotted as a function of time. A) The drying behavior of algae/pine blends containing $30 \%(\boldsymbol{\nabla}) 40 \%(\boldsymbol{\nabla})$, and $50 \%(\diamond)$ algae was compared to that of algae only $(\bullet, 30 \%$ solids, wet basis) and wet pine $(\bullet, 59 \%$ moisture, wb). B) Drying curves of algae blended at $40 \%$ algae and $60 \%$ blendstock, including: sorghum blends $\bullet$ (dry, 66\% moisture, wb), • (fresh, 
80.9\% moisture, wb); corn stover blends (dry, 67.7\% moisture, wb), (fresh, $71.4 \%$ moisture, wb); dry algae blend $\boldsymbol{\Delta}(67.5 \%$ moisture, wb); and algae blended with sand $\diamond(65.8 \%$ moisture, wb). Each blend (panel B) was dried in duplicate with exception of fresh algae blended with dry algae. Displayed is the average of the replicates.

Figure 8. Daily variability in Chlorella algal biomass production at a site in Beaumont, Tx, adapted from Coleman et al. [13]. 30 year average daily algal biomass productivity for Chlorella are plotted for a 350 day production season (blue line) along with maximum (upper, green line) and minimum (lower, red line) algae production values. HTL plant capacity of $21 \mathrm{~g} \mathrm{~m}^{-2}$ day $^{-1}$ (30\% Exceedence) is depicted by the horizontal dashed line. When algae production exceeds plant capacity, drying is required to preserve biomass for later conversion. The gray shaded region represents the expected shortfall in algae production, where HTL plant capacity is greater than algae production. 
Figure 1

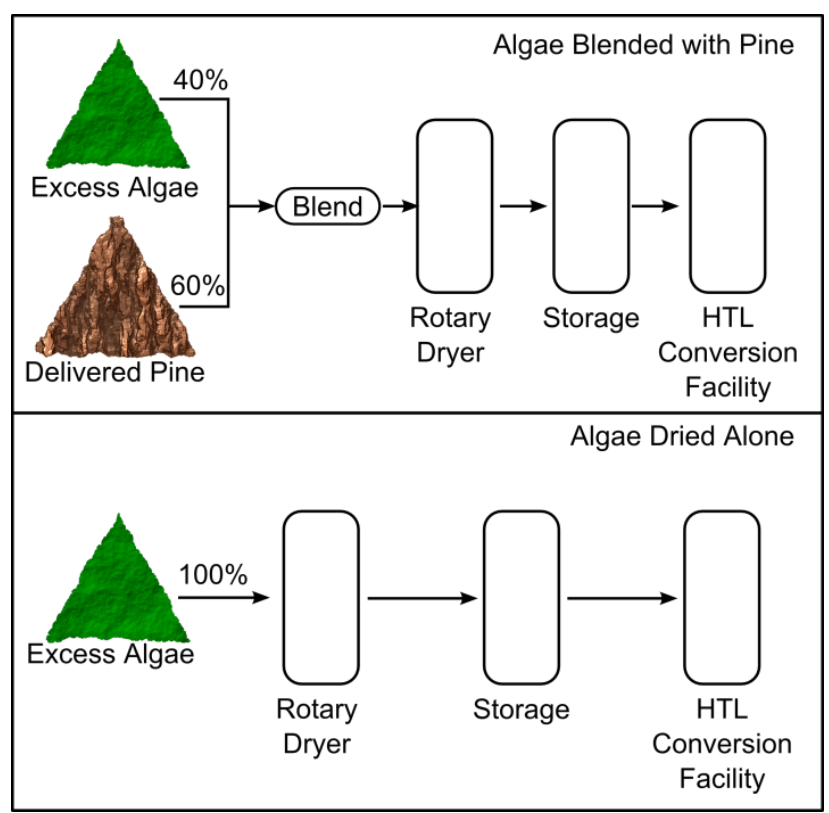


Figure 2

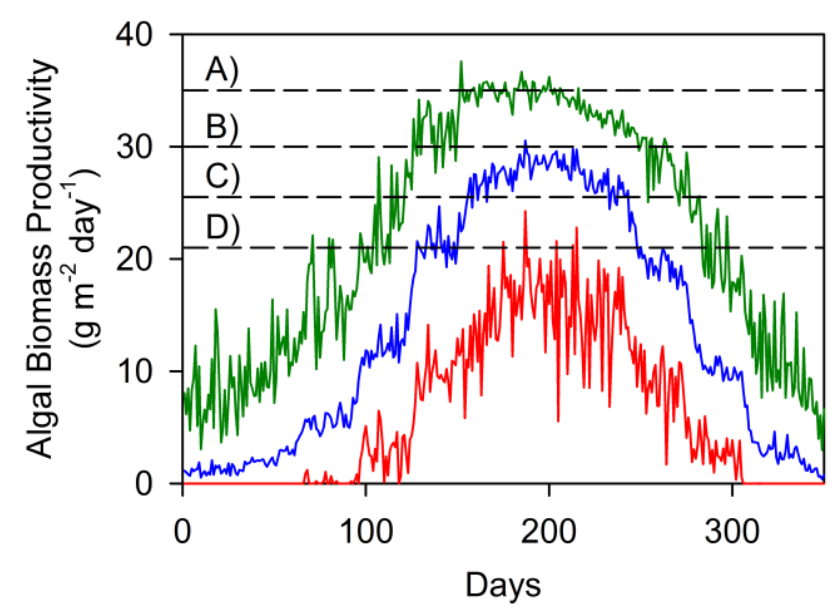


Figure 3

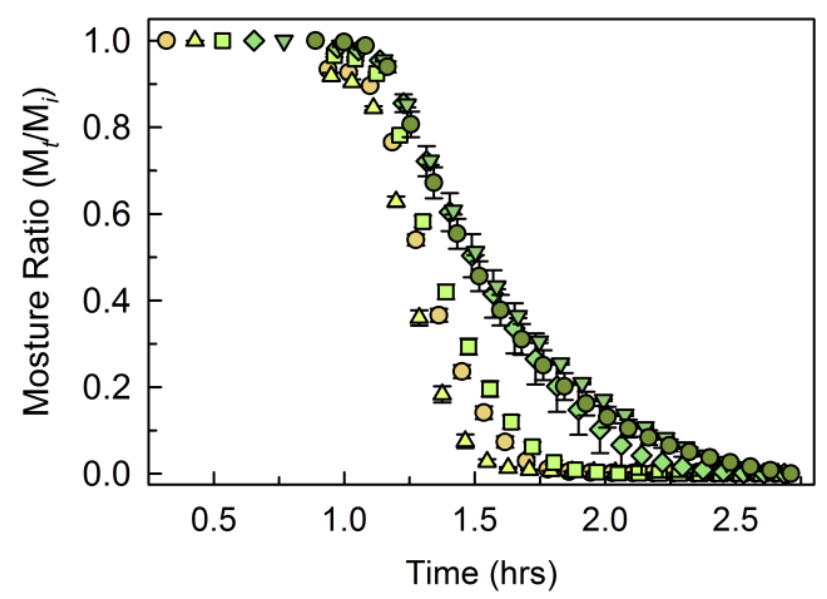


Figure 4

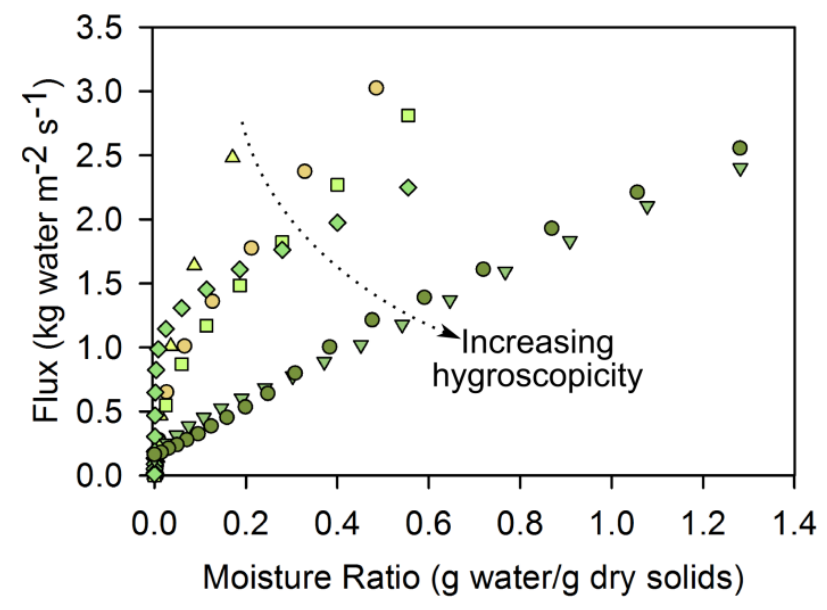


Figure 5
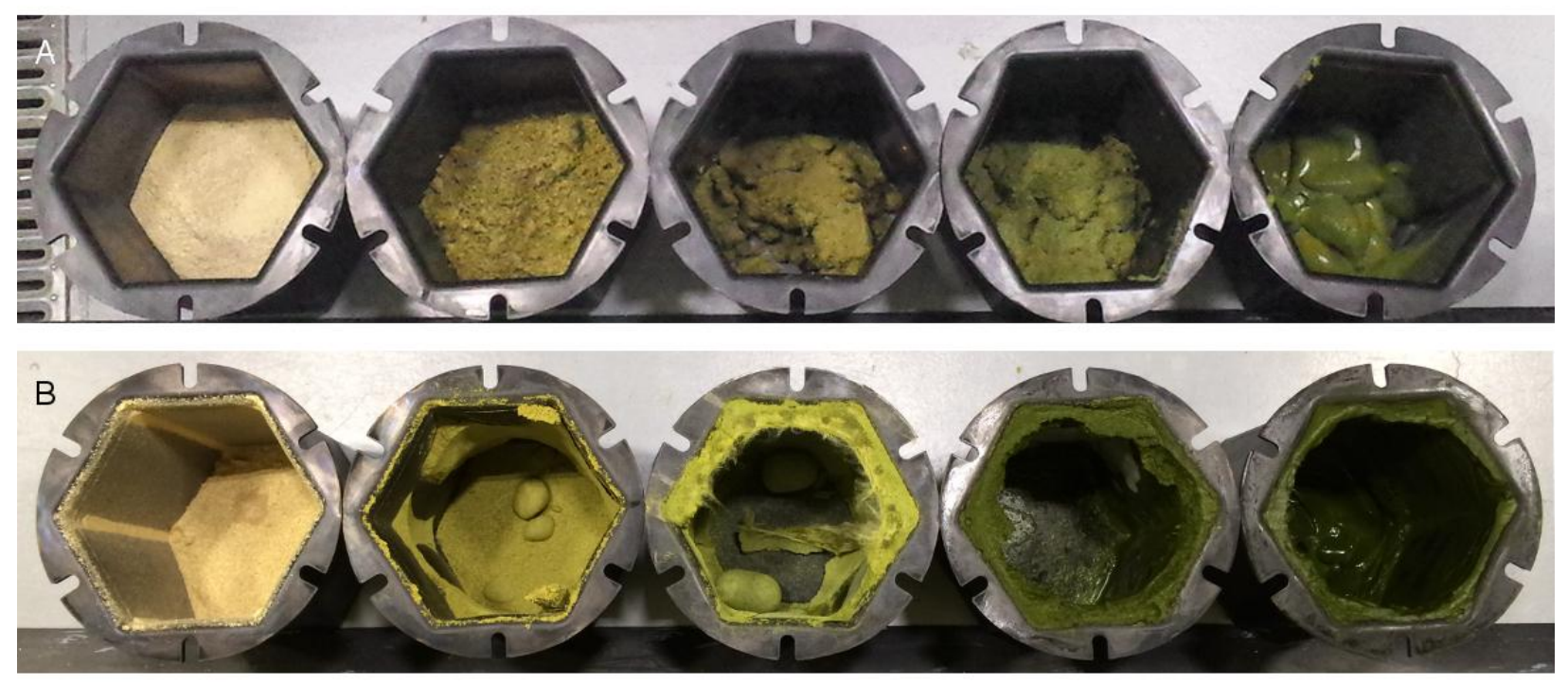
Figure 6
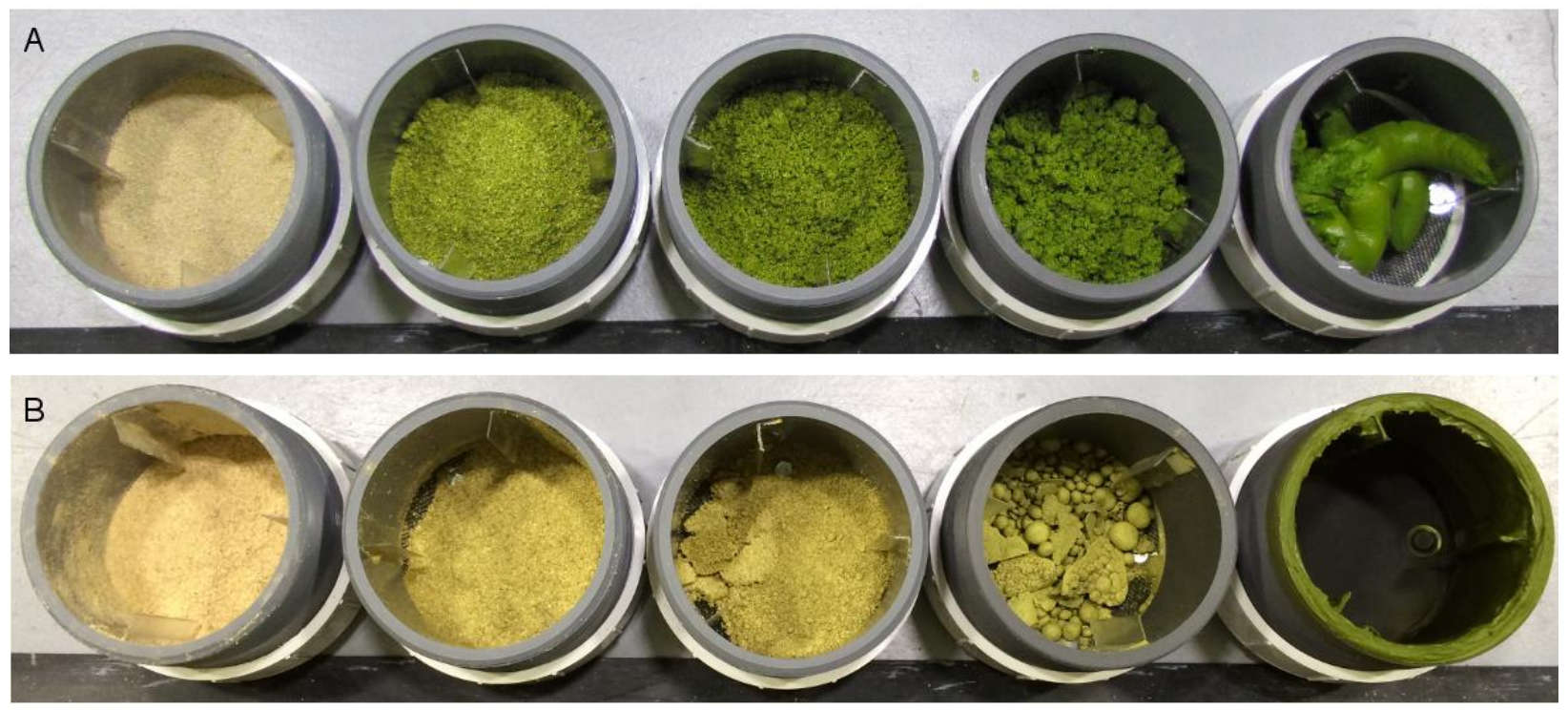
Figure 7
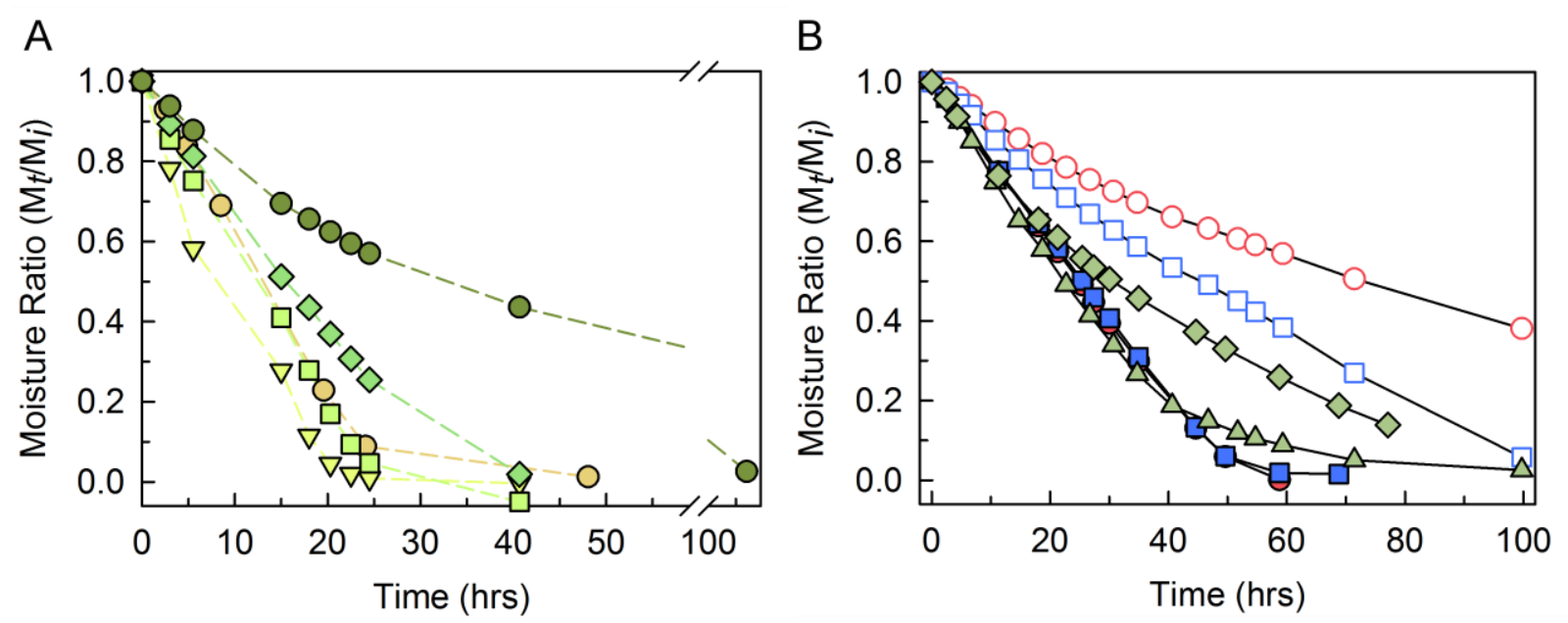
Figure 8

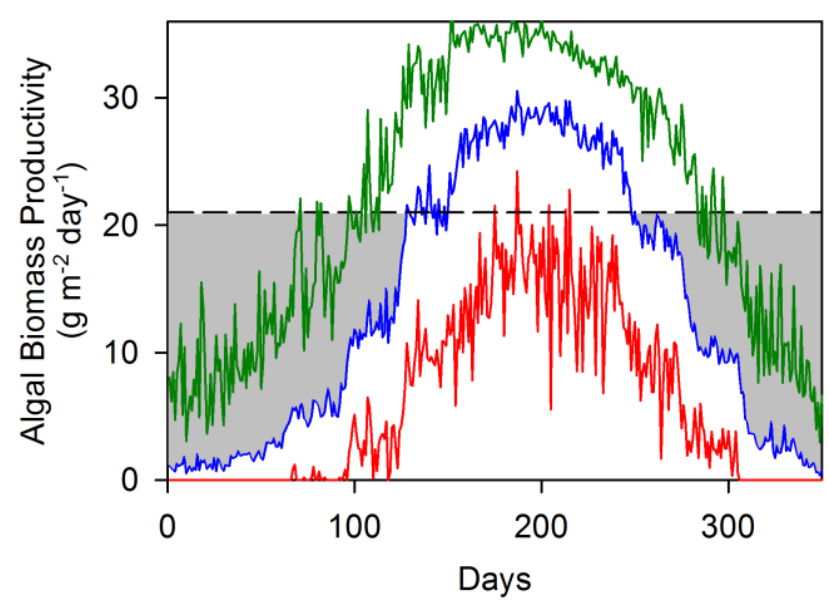

